\title{
Toxic Effects and Molecular Mechanism of Different Types of Silver Nanoparticles to the Aquatic Crustacean Daphnia magna
}

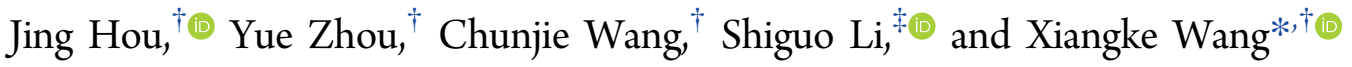 \\ ${ }^{\dagger}$ College of Environmental Science and Engineering, North China Electric Power University, Beijing 102206, China \\ ${ }^{\ddagger}$ Research Center for Eco-Environmental Sciences, Chinese Academy of Science, Beijing 100085, China
}

Supporting Information

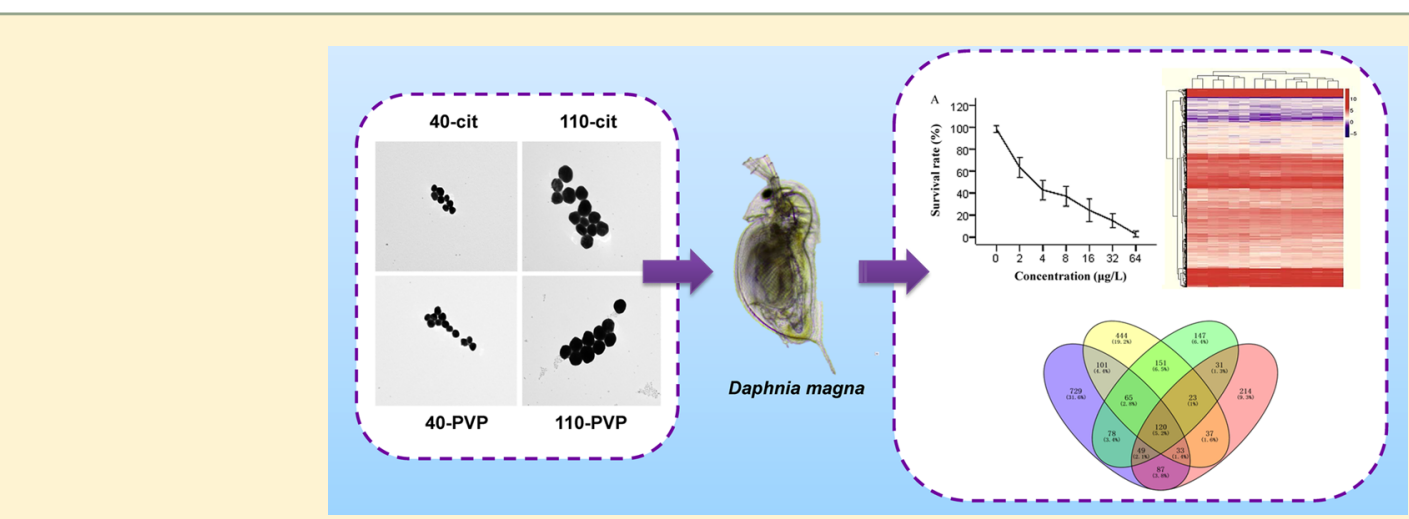

ABSTRACT: Silver nanoparticles (AgNPs) have been assessed to have a high exposure risk for humans and aquatic organisms. Toxicity varies considerably between different types of AgNPs. This study aimed to investigate the toxic effects of AgNPs with different particle sizes (40 and $110 \mathrm{~nm}$ ) and different surface coatings (sodium citrate and polyvinylpyrrolidone, PVP) on Daphnia magna and their mechanisms of action. The results revealed that the citrate-coated AgNPs were more toxic than PVPcoated AgNPs and that the $40 \mathrm{~nm}$ AgNPs were more toxic than the $110 \mathrm{~nm}$ AgNPs. Transcriptome analysis further revealed that the toxic effects of AgNPs on D. magna were related to the mechanisms of ion binding and several metabolic pathways, such as the "RNA polymerase" pathway and the "protein digestion and absorption" pathway. Moreover, the principal component analysis (PAC) results found that surface coating was the major factor that determines the toxicities compared to particle size. These results could help us better understand the possible mechanism of AgNP toxicity in aquatic invertebrates at the transcriptome level and establish an important foundation for revealing the broad impacts of nanoparticles on aquatic environments.

\section{INTRODUCTION}

With the development and commercialization of nanotechnology, silver nanoparticles (AgNPs) have broad application prospects in chemical, optical, medical and other industries ${ }^{1-3}$ due to their advantages of small size, large specific surface area, high catalytic activity, low melting point, good sintering properties, good electrical conductivity, and good antibacterial properties. ${ }^{4-6}$ As a catalyst, AgNPs can change the absorption and conversion of laser energy to the polymer system, resulting in the change of laser dissociation. AgNPs doped in semiconductors or insulators can obtain a large nonlinear polarizability and can be used to make the color filters of optoelectronic devices such as optical switches and advanced optical devices. In addition, AgNPs can be made into medical dressings for most of the trauma treatment to protect against microbial infection. ${ }^{7-9}$ Given these applications, they will eventually enter the freshwater environment such as rivers or lakes and affect aquatic organisms. AgNPs have induced developmental, hepatic, endocrine, and reproductive toxicities in various aquatic organisms such as algae, daphnia, and fish. ${ }^{10-12}$ Once accumulated in aquatic animals, they can enter the human body through the food chain. Therefore, it is necessary to understand the potential impacts of AgNPs on aquatic invertebrates and facilitate a better assessment of their impacts on human health.

The physicochemical properties such as size, ${ }^{13}$ shape ${ }^{14}$ surface coating, ${ }^{15}$ surface charge, ${ }^{16}$ and solution chemistry ${ }^{17,18}$ are important factors for determining AgNP toxicity. Particle size and surface coating have been considered the factors with the greatest influence. For example, $20 \mathrm{~nm}$ AgNPs induced more inflammation or cardiac ischemia and reperfusion injury than $110 \mathrm{~nm}$ AgNPs in Danio rerio. ${ }^{19}$ Locomotor activity experiment demonstrated that Gammarus roeseli exposed to 60 $\mathrm{nm}$ AgNPs exerted a significantly lower activity compared with those exposed to $30 \mathrm{~nm} \mathrm{AgNPs.}{ }^{20}$ The reason why particle size is so determinant of biological toxicity may be dependent on the higher dissolution rate of smaller particles and the pathway

Received: July 31, 2017

Revised: September 30, 2017

Accepted: October 2, 2017

Published: October 2, 2017 
by which particles enter the cell membrane. Kim et al. reported that NPs $<50 \mathrm{~nm}$ can more easily enter cells through endocytosis than NPs $>50 \mathrm{~nm} .^{21}$ It was also demonstrated that $20 \mathrm{~nm}$ AgNPs had significantly greater effects on tail moment, tail DNA intensity and burrowing activity of Nereis diversicolor than $80 \mathrm{~nm}$ AgNPs. ${ }^{22}$ Some contrasting findings demonstrated that AgNPs with larger particle sizes were more toxic. ${ }^{23}$ It is likely that particle size is not a dominant factor in toxicity. For example, Jimenez-Lamana et al. revealed that surface coating rather than size determines the stability of AgNPs in aquatic ecosystems, with a stability order of polyvinylpyrrolidone (PVP)-coated AgNPs > citrate-coated AgNPs > lipoic acidcoated AgNPs. ${ }^{24}$ Similarly, PVP-coated AgNPs were more stable than citrate-coated AgNPs as a result of steric repulsion by the absorbed polymer layer. ${ }^{25}$ Gum-arabic-coated AgNPs has a greater impact on aquatic ecosystems than PVP-coated AgNPs. $^{26}$ The 7 nm PVA-coated AgNPs exhibited higher toxicity to $N$. europaea than $7 \mathrm{~nm} \mathrm{Na} \mathrm{Na}_{2}$ ATP-coated AgNPs. ${ }^{27}$ Thus, it can be seen that the influence of AgNPs with different properties on aquatic organisms is complex. To fully understand the toxic effects of AgNPs on aquatic organisms, the physiological and molecular mechanisms behind these complex effects need to be revealed at different levels and perspectives. Although considerable progress has been made toward elucidating the toxicity levels and biological effects, there is less information regarding the molecular mechanisms of toxicity of AgNPs with both different particle sizes and different surface coatings to aquatic organisms, especially with regard to aquatic invertebrates.

With the rapid development of high-throughput sequencing technologies, the possible physiological functions in specific tissues and organs have explored fully at the transcriptomic level. ${ }^{28-31}$ RNA sequencing (RNA-Seq) has proven to be a rapid and powerful technique, with the low noise, high efficiency, and massive data output enabling high-throughput sequencing of the whole transcriptome. ${ }^{32}$ RNA-Seq can aid in identifying biomarkers of exposure, differentiating toxicity between AgNPs, detecting casual contaminants in environmental samples, and assessing the mechanisms of response to stressors. ${ }^{33,34}$ Although RNA-Seq has been performed in aquatic species such as Pandalus latirostris, ${ }^{35}$ Salmo salar, ${ }^{36}$ Oryzias melastigma, ${ }^{37}$ Labeo rohita, ${ }^{38}$ Lateolabrax japonicas, ${ }^{39}$ Litopenaeus vannamei, ${ }^{40}$ Ostrea edulis, ${ }^{41}$ Pinctada fucata $^{42}$ and Patella vulgate, ${ }^{43}$ the molecular mechanisms underlying the effects of different types of AgNPs on aquatic organisms are still rare.

The objectives of the present study were to investigate toxic effects of different types of AgNPs on an aquatic invertebrate $D$. magna and further explore their mechanisms of action. $D$. magna is widely used as a model organism to evaluate the invertebrate response to toxicants due to its rapid reproduction, short lifespan, and high sensitivity to environmental pollutants. $^{44-46}$ To achieve the above objectives, a RNA-Seq technology was employed to investigate the toxic effects and molecular mechanism of AgNPs (40-cit-AgNP, 110-cit-AgNP, 40-PVP-AgNP, and 110-PVP-AgNP) on D. magna, which will establish an important foundation for revealing the toxicity and toxic mechanism of AgNPs in aquatic invertebrates.

\section{MATERIALS AND METHODS}

Daphnia magna Cultivation. D. magna obtained from the Chinese Research Academy of Environmental Sciences were cultured in an illumination incubator with a photoperiod of 16 $\mathrm{h}$ and $8 \mathrm{~h}$ (light/dark) and a temperature of $21 \pm 1{ }^{\circ} \mathrm{C}$. D. magna were maintained in filtered and sterilized tap water ${ }^{47}$ and fed Scenedesmus obliquus at approximately $0.2 \mathrm{mg}$ of carbon per individual per day. The medium was renewed three times a week and aerated overnight before use. S. obliquus obtained from the Institute of Hydrobiology, Chinese Academy of Sciences were grown in Bold's basal medium (BBM) with and initial $\mathrm{pH}$ of 8.0. Table $\mathrm{S} 1$ summarizes the chemical composition of BBM. The algae were cultured at $25 \pm 1{ }^{\circ} \mathrm{C}$ with a light intensity of $2500(\mathrm{l} \times)$ and a photoperiod of $14 \mathrm{~h}$ and $10 \mathrm{~h}$ (light/dark). The algal cell density was determined using a hemocytometer under a trinocular microscope (B204TR, Chongqing, China) at a magnification of $400 \times$.

Silver Nanoparticle Characterization. Citrate-coated AgNPs (sodium citrate as a stabilizer) with average particle sizes of 40 and $110 \mathrm{~nm}$ (40-cit-AgNP and 110-cit-AgNP) and PVP-coated AgNPs (0.3\% polyvinylpyrrolidone) with average particle sizes of 40 and $110 \mathrm{~nm}$ (40-PVP-AgNP and 110-PVPAgNP) were obtained from nanoComposix (San Diego, CA). Transmission electron microscope (TEM) analysis was used to characterize the size and shape of the AgNPs after 0 and $24 \mathrm{~h}$ of dispersion in the test medium by placing a droplet of the AgNPs on a TEM grid followed by obtaining images using a TEM (Hitachi H-7650B, Japan) at an accelerating voltage of $120 \mathrm{kV}$. The hydrodynamic size and zeta potential of the AgNPs dispersed in the test medium were measured at 0 and $24 \mathrm{~h}$ using a Zetasizer (Nano ZS, Malvern Instruments). Each time point consisted of three replicates, and five consecutive measurements were made per replicate. Dissolution of the AgNPs was determined by separating dissolved silver from the AgNPs using centrifugal ultrafiltration with a $30-\mathrm{kDa}$ filter (Millipore Amicon Ultra). ${ }^{48}$ The dispersions were centrifuged at $3000 \mathrm{~g}$ for $60 \mathrm{~min}$ (Centrifuge 5424, Eppendorf, Germany), and the dissolved silver present in the filtrate was acidified and analyzed in triplicate at $6,12,18$, and $24 \mathrm{~h}$ by inductively coupled plasma atomic emission spectroscopy (ICP-AES; SPECTRO Analytical Instruments GmbH, Germany).

Acute Toxicity Test. D. magna toxicity tests were slightly modified from the United States Environmental Protection Agency (U.S. EPA) Whole Effluent Toxicity guidelines. ${ }^{49}$ The 14 day old $D$. magna were exposed to six different concentrations $(0,2,4,8,16,32$, and $64 \mu \mathrm{g} / \mathrm{L})$ of AgNPs. Each concentration consisted of $30 \mathrm{D}$. magna with in each of six replicates. D. magna were incubated in incubator without feeding during the $24 \mathrm{~h}$ exposure period and examined for lethality after $24 \mathrm{~h}$. The probit analysis method was employed to estimate the median lethal concentration $\left(\mathrm{LC}_{50}\right)$ values. All subsequent assays were performed using $2 \mu \mathrm{g} / \mathrm{L}$ (close to $1 / 10$ $\mathrm{LC}_{50}$ ) of 40-cit-AgNP, 110-cit-AgNP, 40-PVP-AgNP, and 110PVP-AgNP because this level was below that which causes nonspecific gene expression responses. ${ }^{50}$ At predetermined intervals $(6,12,18$, and $24 \mathrm{~h})$, Thirty D. magna was sampled from each treatment and sacrificed to measure silver concentration in the body. A total of three biological replicates were conducted for each treatment.

RNA Sequencing. Exposures were performed on D. magna using $2 \mu \mathrm{g} / \mathrm{L}$ (close to $1 / 10 \mathrm{LC}_{50}$ ) of 40 -cit-AgNP, 110-citAgNP, 40-PVP-AgNP, and 110-PVP-AgNP for $24 \mathrm{~h}$. A total of 3014 day old $D$. magna were pooled together to generate one sample. A total of three biological replicates were conducted for each treatment. The detailed RNA-Seq method, including total RNA extraction, mRNA enrichment, mRNA fragment, cDNA synthesis, library construction, and Illumina sequencing, is 


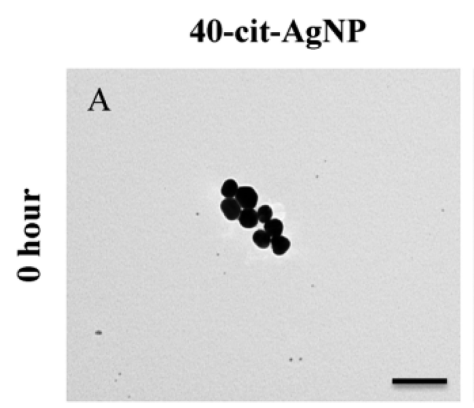

110-cit-AgNP
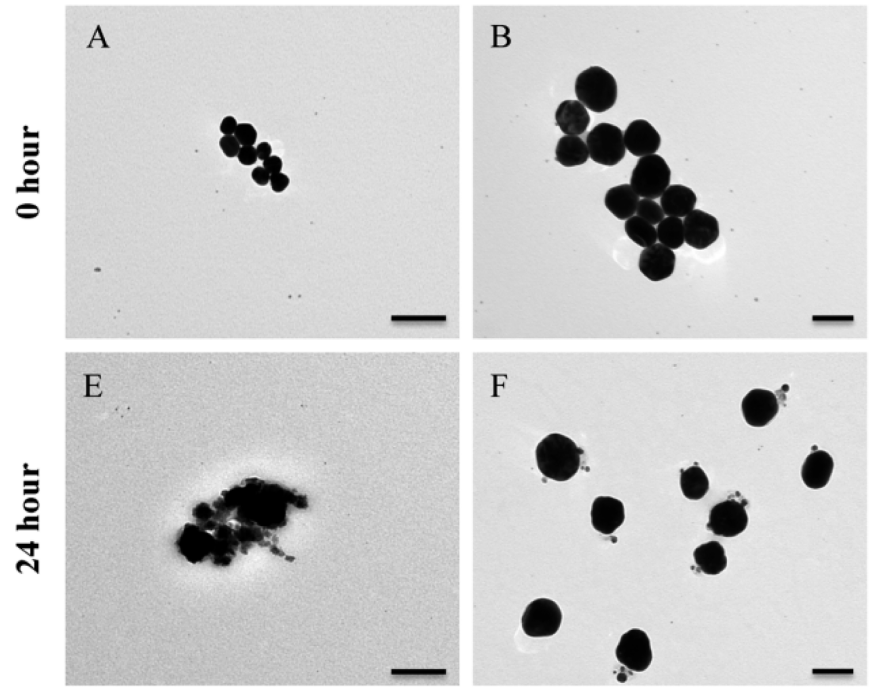

40-PVP-AgNP

C

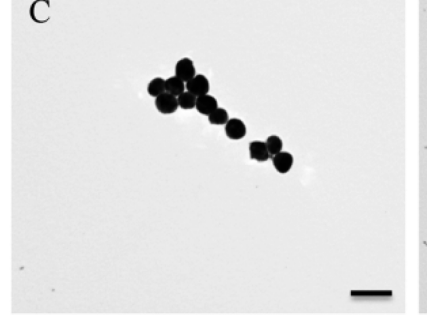

G
110-PVP-AgNP
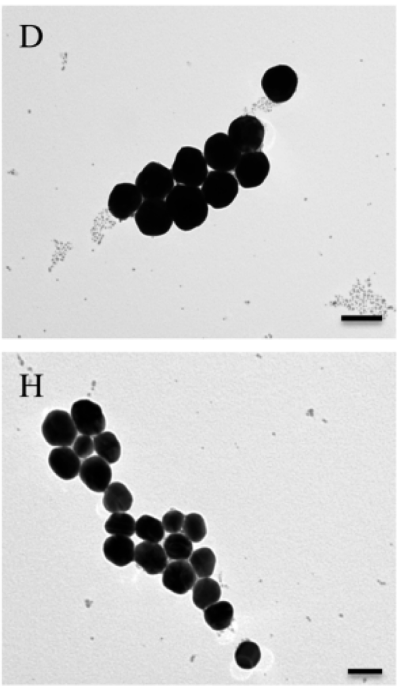

Figure 1. TEM images of the silver nanoparticles after 0 and $24 \mathrm{~h}$ of dispersion in the experimental medium that reveal the primary sizes, shapes, and agglomeration states of the AgNPs. (a) 40-cit-AgNP after $0 \mathrm{~h}$ of exposure. (b) 110-cit-AgNP after $0 \mathrm{~h}$ of exposure. (c) 40 -PVP-AgNP after 0 h of exposure. (d) 110-PVP-AgNP after $0 \mathrm{~h}$ of exposure. (e) 40-cit-AgNP after $24 \mathrm{~h}$ of exposure. (f) 110-cit-AgNP after 24 h of exposure. (g) 40-PVPAgNP after $24 \mathrm{~h}$ of exposure. (h) 110-PVP-AgNP after $24 \mathrm{~h}$ of exposure. Bar $=100 \mathrm{~nm}$.

shown in the Supporting Information. RNA-Seq library sequencing was carried out on an Illumina HiSeq 4000 instrument with 50 base pairs (bp) based on the cDNA library of D. magna. If the result passed quality control, the NOISeq method was used to screen for differentially expressed genes (DEGs) according to the following criteria: fold change of $>1.2$ and $p$-value of $>0.5$. The Web site (http://bioinfogp.cnb.csic. es/tools/venny/index.html) was used to generate the Venn diagram.

Gene Ontology Enrichment Analysis. Gene ontology (GO) enrichment analysis provided all GO terms that were significantly enriched in a list of DEGs. All DEGs were mapped to GO terms, and gene numbers were calculated for every term in the database (http://www.geneontology.org/). Significantly enriched GO terms for the input list of DEGs were calculated using the hypergeometric test with $p$-value correction based on GO::TermFinder (http://search.cpan.org/ sherlock/GOTermFinder/http://search.cpan.org/ sherlock/GOTermFinder).

Kyoto Encyclopedia of Genes and Genomes Pathway Analysis. The KEGG was used to identify the biological pathways of DEGs that were affected by AgNPs via comparison to the background genome, which helped further predict the functions of these DEGs. A KEGG enrichment analysis (hypergeometric test, $q$-value of $<0.05$ ) was performed on all DEGs using the KEGG database (http://www.genome.jp/ kegg/).

Hierarchical Clustering Analysis and Principal Component Analysis. Hierarchical clustering analysis (HCA) is a chemometric tool used to calculate the distance between samples via the sum of squares of deviations algorithm. Genes with similar expression values are clustered at both the row and the column level. Only genes that were expressed in all samples of the cluster plan were used to build the heatmap. The heatmap was produced with cluster and javaTreeview software. Expression values for each transcript were $\log _{2}$-transformed before cluster formation. The heatmap was clustered using the complete linkage hierarchical analysis based on Euclidean distance. For the principal component analysis (PCA), all data were first unit-variance scaled and mean centered. A twocomponent model was selected for the distance measurement, which scattered in oval shapes when the data sets were strongly related.

Real-Time Quantitative PCR. To validate the reliability of the RNA-Seq data, real-time quantitative polymerase chain reaction (RT-PCR) was performed. A total of eight DEGs with various expression patterns, including two DEGs involved in 40-cit-AgNP, two DEGs involved in 110-cit-AgNP, two DEGs involved in 40-PVP-AgNP, and two DEGs involved in 110PVP-AgNP, were selected for validation. Total RNA was extracted and purified as described above. The first-strand cDNA was synthesized using the Superscript III First-Strand Synthesis kit (Invitrogen, Carlsbad, CA) following the manufacturer's instructions. RT-qPCR was performed using SYBR Premix Ex TaqII (Takara, Japan) on a 7500 Fast RealTime PCR system (Applied Biosystems, Foster, CA). The cycling conditions were as follows: one cycle of $50{ }^{\circ} \mathrm{C}$ for $5 \mathrm{~min}$ and $95^{\circ} \mathrm{C}$ for $2 \mathrm{~min}$ for initial denaturation, and 45 cycles of 95 ${ }^{\circ} \mathrm{C}$ for $15 \mathrm{~s}$ and $60{ }^{\circ} \mathrm{C}$ for $30 \mathrm{~s}$. Each sample was run in triplicate. DmACTIN was used as a reference gene, and primers were designed with Primer-BLAST (www.ncbi.nlm.nih.gov/ tools/primer-blast/). The relative quantitative method $\left(2^{-\Delta \Delta C T}\right)$ was used to calculate the fold change of the selected genes. Data are expressed as the mean \pm standard error from samples performed in triplicate.

\section{RESULTS}

Physicochemical Characterization of AgNPs. Figure 1 displays the size, shape, and agglomeration state of the four types of AgNPs after 0 and $24 \mathrm{~h}$ of dispersion in the D. magna test medium. The representative TEM images demonstrated that the primary AgNPs were spherical in shape and uniform in size, confirming the manufacturer's description of 40 or $110 \mathrm{~nm}$ for all four particles (Figure 1a-d). After $24 \mathrm{~h}$ of dispersion, the 40-cit-AgNP aggregated significantly into irregular shapes (Figure 1e). The 110-cit-AgNPs were discrete without 
Table 1. Silver Nanoparticles Hydrodynamic Size and $\zeta$ Potential in the Growth Medium ${ }^{a}$

\begin{tabular}{|c|c|c|c|c|}
\hline \multirow[b]{2}{*}{ nanoparticle type } & \multicolumn{2}{|c|}{ hydrodynamic size (nm) } & \multicolumn{2}{|c|}{$\zeta$ potential $(\mathrm{mV})$} \\
\hline & $0 \mathrm{~h}$ & $24 \mathrm{~h}$ & $0 \mathrm{~h}$ & $24 \mathrm{~h}$ \\
\hline 40-cit-AgNP & $43.2 \pm 0.3$ & $209.7 \pm 26.5$ & $-31.3 \pm 3.9$ & $-11.3 \pm 3.2$ \\
\hline 110-cit-AgNP & $94.3 \pm 0.6$ & $89.4 \pm 5.6$ & $-36.7 \pm 2.8$ & $-18.6 \pm 2.2$ \\
\hline 40-PVP-AgNP & $45.2 \pm 0.2$ & $38.7 \pm 3.1$ & $-27.7 \pm 3.6$ & $-28.3 \pm 2.4$ \\
\hline 110-PVP-AgNP & $89.6 \pm 0.9$ & $86.1 \pm 0.7$ & $-33.2 \pm 1.5$ & $-31.6 \pm 2.6$ \\
\hline
\end{tabular}

aggregation, although some small spherical particles were obviously dispersed around each nanoparticle (Figure 1f). Both 40-PVP-AgNP and 110-PVP-AgNP showed a monodisperse nanoparticle size distribution and spherical form without clusters or aggregates, indicating greater stabilization of the PVP-coated AgNPs (Figure 1g,h).

The TEM results were also confirmed by the hydrodynamic sizes and $\zeta$ potentials (Table 1 ). The hydrodynamic sizes of 40cit-AgNP, 110-cit-AgNP, 40-PVP-AgNP, and 110-PVP-AgNP in the $D$. magna test medium were found to change from 43.2 $\pm 0.3,94.3 \pm 0.6,45.2 \pm 0.2$, and $89.6 \pm 0.9 \mathrm{~nm}$ after $0 \mathrm{~h}$ of exposure to $209.7 \pm 26.5,89.4 \pm 5.6,38.7 \pm 3.1$, and $86.1 \pm 0.7$ $\mathrm{nm}$ after $24 \mathrm{~h}$ of exposure, respectively. The $\zeta$ potentials were used to characterize the stability of the dispersed system. The absolute value of the $\zeta$ potentials for 40 -cit-AgNP and 110-citAgNP decreased from $-31.3 \pm 3.9$ and $-36.7 \pm 2.8$ after $0 \mathrm{~h}$ of exposure to $-11.3 \pm 3.2$ and $-18.6 \pm 2.2$ after $24 \mathrm{~h}$ of exposure, respectively, suggesting a significant decrease in the AgNP stability. The 40-PVP-AgNP and 110-PVP-AgNP had $\zeta$ potentials of $-28.3 \pm 2.4$ and $-31.6 \pm 2.6$ after $24 \mathrm{~h}$ of exposure, indicating good stability of the PVP-coated AgNPs.

Acute Toxicity. The $24 \mathrm{~h} \mathrm{LC}_{50}$ values for 40 -cit-AgNP, 110 cit-AgNP, 40-PVP-AgNP, and 110-PVP-AgNP were 8.90, 17.43, 24.97, and $38.35 \mu \mathrm{g} / \mathrm{L}$, respectively (Figure S1). The rank order of toxicity to $D$. magna, determined based on the $\mathrm{LC}_{50}$ values, was 40-cit-AgNP > 110-cit-AgNP > 40-PVP-AgNP $>$ 110-PVP-AgNP. A pair of trends related to toxicity were summarized: citrate-coated AgNPs were more toxic than PVPcoated AgNPs, and $40 \mathrm{~nm}$ AgNPs were more toxic than 110 nm AgNPs.

Dissolution of Silver Nanoparticles. The particle dissolution rates were determined because particle dissolution plays a key role in the toxicity of AgNPs to aquatic organisms. All four particles demonstrated a significant increase in $\mathrm{Ag}$ shedding after $6,12,18$, and $24 \mathrm{~h}$ of incubation in the D. magna test medium (Figure 2). The dissolution rates within $24 \mathrm{~h}$ followed the sequence 40-cit-AgNP > 110-cit-AgNP > 40-PVPAgNP > 110-PVP-AgNP. The citrate-coated AgNPs exhibited a higher level of dissolution than the PVP-coated AgNPs, and the $40 \mathrm{~nm}$ AgNPs were more rapid than the $110 \mathrm{~nm}$ AgNPs for the same type of surface coating with the exception of 40-PVPAgNP at $6 \mathrm{~h}$ and 40 -cit-AgNP at $24 \mathrm{~h}$.

Uptake of Silver Nanoparticles. As shown in Figure 3, the uptake of the four types of AgNPs showed a general increase during the $24 \mathrm{~h}$. The uptake of $40 \mathrm{~nm}$ AgNPs by $D$. magna is greater than that of $110 \mathrm{~nm} \mathrm{AgNPs}$ at the same time point, while there was no significant difference in the uptake between citrate-coated AgNPs and PVP-coated AgNPs. The difference in body burden during this period could be explained by particle size. The body burden values of 40 -cit-AgNP at 6 , 12,18 , and $24 \mathrm{~h}$ increased by $116 \%, 138 \%, 108 \%$ and $122 \%$ compared to 110 -cit-AgNP. The body burden values of 40 -

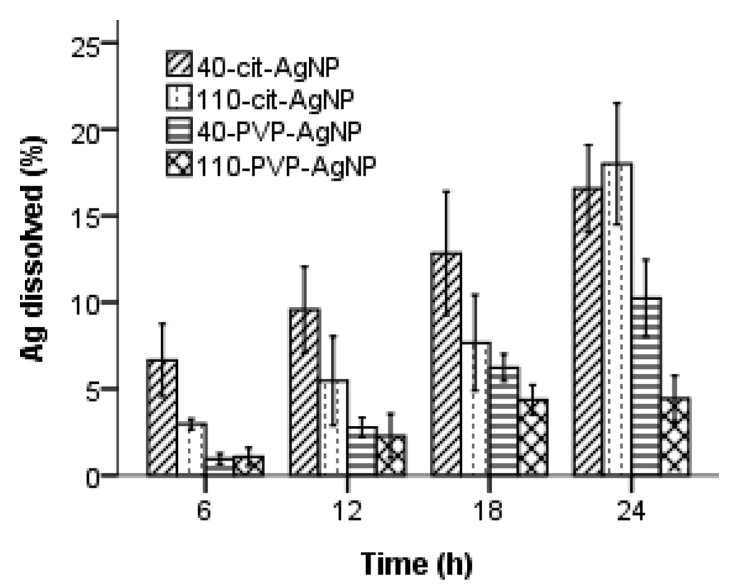

Figure 2. Dissolution characteristics of 40-cit-AgNP, 110-cit-AgNP, 40-PVP-AgNP, and 110-PVP-AgNP in the growth medium at $t=6,12$, 18, and $24 \mathrm{~h}$. Error bars represent the standard deviations determined from three independent experiments.

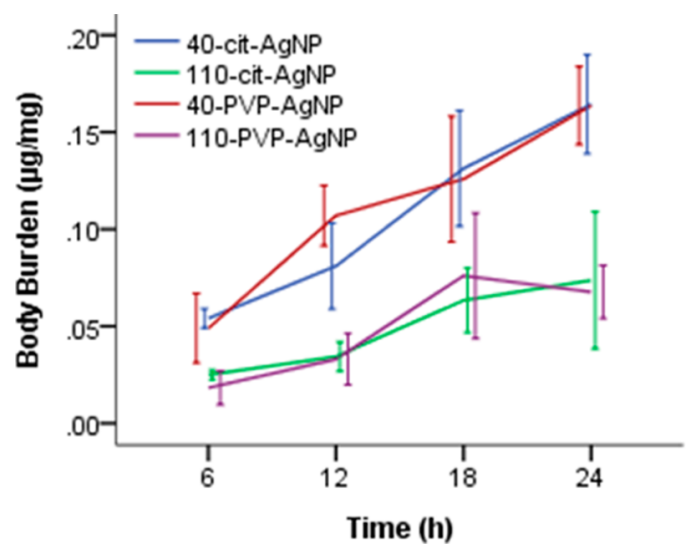

Figure 3. Silver nanoparticles uptake by Daphnia magna exposed to 40-cit-AgNP, 110-cit-AgNP, 40-PVP-AgNP, and 110-PVP-AgNP for $24 \mathrm{~h}$. Error bars represent standard deviations determined from three independent experiments.

PVP-AgNP at 6, 12, 18, and $24 \mathrm{~h}$ increased by $172 \%, 224 \%$, $66 \%$ and $141 \%$ compared to $110-$ PVP-AgNP.

Analysis of Differentially Expressed Genes. To discriminate the toxic effects induced by the different types of AgNPs, a total of 1262, 974, 664, and 594 DEGs for 40-citAgNP, 110-cit-AgNP, 40-PVP-AgNP, and 110-PVP-AgNP were identified using a cutoff of $p$-value $>0.5$ and fold change $>1.2$ (Table 2). The lists of DEGs for each exposure are presented in File S1. The gene expression data were correlated with the acute toxicity data. The 40-cit-AgNP caused the most abundant candidate genes, followed by 110-cit-AgNP and then 40-PVPAgNP; 110-PVP-AgNP resulted in the weakest response. The number of down-regulated genes exceeded the number of up- 
Table 2. Numbers of Total and Up- and Down-Regulated Genes Differentially Expressed from Different AgNP Exposures at a $p$-Value of $>0.5$ and Fold Change of $>1.2$

\begin{tabular}{lrccc}
$\begin{array}{c}\text { differentially expressed } \\
\text { genes }\end{array}$ & $\begin{array}{c}40 \text {-cit- } \\
\text { AgNP }\end{array}$ & $\begin{array}{c}\text { 110-cit- } \\
\text { AgNP }\end{array}$ & $\begin{array}{c}\text { 40-PVP- } \\
\text { AgNP }\end{array}$ & $\begin{array}{c}\text { 110-PVP- } \\
\text { AgNP }\end{array}$ \\
\hline up-regulation & 310 & 238 & 186 & 183 \\
down-regulation & 952 & 736 & 478 & 411 \\
total & 1262 & 974 & 664 & 594 \\
\hline
\end{tabular}

regulated genes for all four exposures. The distributions and possible relations of DEGs between all treatments are demonstrated in a Venn diagram (Figure 4). Venn diagram

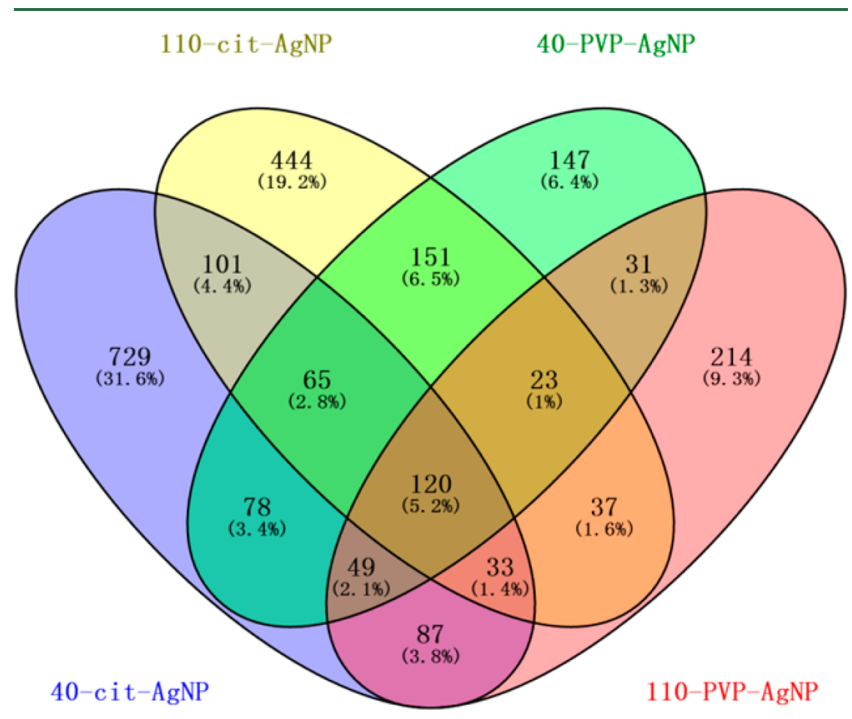

Figure 4. Venn diagram of the differentially expressed genes elicited by 40-cit-AgNP, 110-cit-AgNP, 40-PVP-AgNP, and 110-PVP-AgNP. Each oval represents a different treatment. Overlapping regions show the number and percentage of common genes regulated by the different AgNP treatments.

analysis revealed that 120 (5.2\%) DEGs were commonly altered by all four exposures. There were 729 (31.6\%), 444 (19.2\%), 147 (6.4\%), and 214 (9.3\%) DEGs for 40-cit-AgNP,
110-cit-AgNP, 40-PVP-AgNP, and 110-PVP-AgNP, respectively, that were altered by only one of the treatments and not by any other treatments. The number of DEGs altered by citrate-coated AgNPs (319 genes, 13.8\%) was greater than the number of altered by PVP-coated AgNPs (223 genes, 9.6\%). Similarly, the number of DEGs altered by $40 \mathrm{~nm}$ AgNPs (312 genes, $13.5 \%)$ was greater than the number altered by $110 \mathrm{~nm}$ AgNPs (213 genes, 9.2\%). Sequencing data have been submitted to the Sequence Read Archive (SRA, https:// submit.ncbi.nlm.nih.gov/subs/sra/) under accession no. PRJNA389206.

GO Enrichment Analysis of DEGs. To further study the functions of the DEGs, they are subjected to GO functional enrichment analysis, which is a gene-function classification system used to describe the properties of genes and their products according to three characteristics: cellular components, molecular function, and biological processes. The GO enrichment analysis results indicated that $29,15,8$, and $24 \mathrm{GO}$ terms were significantly enriched in the $D$. magna exposed to 40-cit-AgNP, 110-cit-AgNP, 40-PVP-AgNP, and 110-PVPAgNP, respectively (File S2). The GO terms that existed in at least two exposure conditions are summarized in Figure 5. Most of the GO terms are related to ion binding. Transition metal ion binding (GO: 0046914), ion binding (GO: 0043167), and iron ion binding (GO: 0005506) are the common GO terms for three of the exposure conditions. Cation binding (GO: 0043169) is the only common GO term for the $40 \mathrm{~nm}$ AgNPs (40-cit-AgNP and 40-PVP-AgNP). Protein complex (GO: 0043234), transporter activity (GO: 0005215), substrate-specific transporter activity (GO: 0022892), gas transport (GO: 0015669), single-organism transport (GO: 0044765), and single-organism localization (GO: 1902578) are common GO terms for the $110 \mathrm{~nm} \mathrm{AgNPs}$ (110-cit-AgNP and 110-PVP-AgNP). Notably, gas transport (GO: 0015669) is the most statistically significant term for both 110-cit-AgNP $\left(p=7.61 \times 10^{-9}\right)$ and 110-PVP-AgNP $(p=$ $\left.3.05 \times 10^{-8}\right)$.

KEGG Pathway Analysis of DEGs. KEGG analysis was further performed to identify the enrichment pathways in $D$. magna for each treatment. DEGs for 40-cit-AgNP, 110-cit-

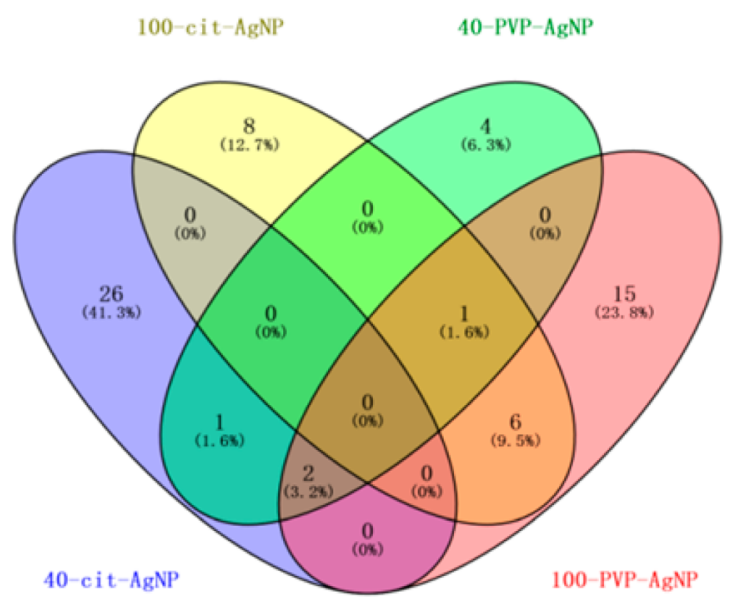

2 common GO terms in "40-cit-AgNP", "40-PVP-AgNP" and "100-PVP-AgNP":

$>$ transition metal ion binding (GO:0046914)

$>$ ion binding (GO:0043167)

1 common GO terms in "100-cit-AgNP", "40-PVP-AgNP" and "100-PVP-AgNP":

$>$ iron ion binding (GO:0005506)

1 common GO term in "40-cit-AgNP" and "40-PVP-AgNP":

$>$ cation binding (GO:0043169)

6 common GO terms in "100-cit-AgNP" and "100-PVP-AgNP":

$>$ protein complex (GO:0043234)

$>$ transporter activity (GO:0005215)

$>$ substrate-specific transporter activity (GO:0022892)

$>$ gas transport (GO:0015669)

$>$ single-organism transport (GO:0044765)

> single-organism localization (GO:1902578)

Figure 5. Venn diagram showing the numbers of significantly enriched GO terms after 40-cit-AgNP, 110-cit-AgNP, 40-PVP-AgNP, and 110-PVPAgNP exposure. The GO terms that are common to at least two conditions are summarized at the right. 
AgNP, 40-PVP-AgNP, and 110-PVP-AgNP were found to be enriched in 252, 225, 184, and, 192 KEGG pathways, respectively (File S3). Taking a $q$-value of $<0.05$ as a threshold, the most represented pathways are summarized in Table 3.

Table 3. Significantly Enriched KEGG Pathways of DEGs from D. magna Exposed to AgNPs ${ }^{a}$

\begin{tabular}{|c|c|c|c|}
\hline treatment & affected biological pathway & $q$-value & $\begin{array}{l}\text { DEGs with } \\
\text { pathway } \\
\text { annotation }\end{array}$ \\
\hline \multirow{4}{*}{$\begin{array}{l}\text { 40-cit- } \\
\text { AgNP }\end{array}$} & hippo signaling pathway-fly & 0.0211 & $18(2.74 \%)$ \\
\hline & $\begin{array}{l}\text { endocrine and other factor- } \\
\text { regulated calcium } \\
\text { reabsorption }\end{array}$ & 0.0323 & $11(1.67 \%)$ \\
\hline & hippo signaling pathway & 0.0323 & $17(2.58 \%)$ \\
\hline & RNA polymerase & 0.0467 & $17(2.58 \%)$ \\
\hline \multirow{6}{*}{$\begin{array}{l}\text { 110-cit- } \\
\text { AgNP }\end{array}$} & RNA polymerase & $8.55 \times 10^{-30}$ & $46(10.8 \%)$ \\
\hline & pyrimidine metabolism & $9.92 \times 10^{-18}$ & $52(12.21 \%)$ \\
\hline & purine metabolism & $1.89 \times 10^{-11}$ & $58(13.62 \%)$ \\
\hline & $\begin{array}{l}\text { amino sugar and nucleotide } \\
\text { sugar metabolism }\end{array}$ & 0.0001 & $17(3.99 \%)$ \\
\hline & metabolic pathways & 0.0013 & $116(27.23 \%)$ \\
\hline & ECM-receptor interaction & 0.0238 & $15(3.52 \%)$ \\
\hline \multirow{5}{*}{$\begin{array}{l}\text { 40-PVP- } \\
\text { AgNP }\end{array}$} & pyrimidine metabolism & $1.60 \times 10^{-5}$ & $25(8.87 \%)$ \\
\hline & lysosome & $8.62 \times 10^{-5}$ & $17(6.03 \%)$ \\
\hline & $\begin{array}{l}\text { protein digestion and } \\
\text { absorption }\end{array}$ & 0.0004 & $21(7.45 \%)$ \\
\hline & purine metabolism & 0.0020 & $29(10.28 \%)$ \\
\hline & $\begin{array}{l}\text { complement and coagulation } \\
\text { cascades }\end{array}$ & 0.0453 & $6(2.13 \%)$ \\
\hline $\begin{array}{l}\text { 110-PVP- } \\
\text { AgNP }\end{array}$ & $\begin{array}{l}\text { protein digestion and } \\
\text { absorption }\end{array}$ & $7.64 \times 10^{-5}$ & $22(8.66 \%)$ \\
\hline
\end{tabular}

${ }^{a}$ The $q$-values less than 0.05 were considered as significantly enriched terms.
Hippo signaling $(q=0.0211)$ is the most statistically significant pathway for 40-cit-AgNP. RNA polymerase $\left(q=8.55 \times 10^{-30}\right)$ is the most statistically significant pathway for 110-cit-AgNP. Pyrimidine metabolism $\left(q=1.60 \times 10^{-5}\right)$ and lysosom $(q=$ $\left.8.62 \times 10^{-5}\right)$ are the most statistically significant pathways for 40-PVP-AgNP. Protein digestion and absorption $(q=7.64 \times$ $10^{-5}$ ) is the most statistically significant pathway for 110-PVPAgNP. RNA polymerase is the only in-common pathway for the citrate-coated AgNPs (40-cit-AgNP and 110-cit-AgNP). Protein digestion and absorption is the only in-common pathway for the PVP-coated AgNPs (40-PVP-AgNP and 110PVP-AgNP).

Hierarchical Clustering Analysis. HCA was performed to obtain more information about the similarities or differences between groups and between samples by calculating the distance between them. As shown in Figure S2, the dendrogram presented in the top axis was generated by identifying relatively homogeneous clusters of samples on the basis of their similarities. Each row represents a single gene, and each column represents an experimental sample. Different colors indicate different gene expression levels. As seen in the dendrogram, the expression profiles induced by the 15 samples were clustered into two distinct clusters. The left cluster can be further divided into two subclusters. One is composed of two 110-PVP-AgNP samples. The other is composed of one 110PVP-AgNP sample and three control samples. The right cluster is formed by the 40-cit-AgNP group, 40-PVP-AgNP group, and 110 -cit-AgNP group. A total of three replicate samples are clustered in one group. Each group is independent of the others and has no overlap. The 40 -cit-AgNP group is clearly discernible from the rest of groups and forms a subcluster. The 110-cit-AgNP and 40-PVP-AgNP groups are mixed to form another subcluster. These results indicate that most of the treatments exhibited a good reproducibility, and the different types of AgNPs can be discriminated from each other at relatively low concentrations.

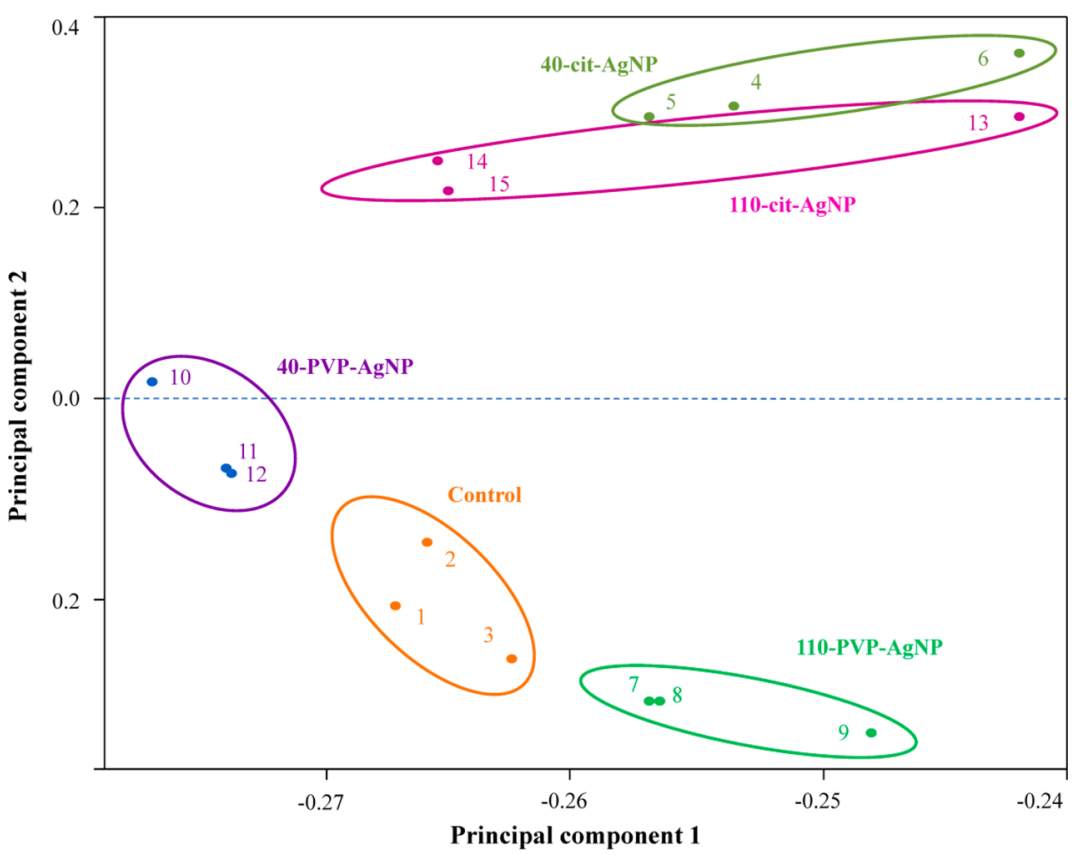

Figure 6. Principal component analysis of the 15 data sets. Each dot represents one sample. The samples are clustered according to the value distribution of component 1 and component 2 . 
Principal Component Analysis. PCA is commonly used to obtain more information about the main variables and classify different samples by reducing redundant information in the data. As illustrated in Figure 6, dots with the same color represent the same treatment. Each treatment consists of three replicates. The PCA result is in accord with the HCA result. Dots with the same color are relatively close to each other and far from the other dots, indicating a closer relationship among the replicate samples, thus further verifying the reproducibility and reliability of the RNA-Seq data. The 15 sample dots are classified into 5 groups. The principal component 1 values for all of the samples are negative. Note that principal component 2 separates 40 -cit-AgNP and 110-cit-AgNP (positive scores) from 40-PVP-AgNP and 110-PVP-AgNP (negative scores), the former being citrate-coated AgNPs and the latter being PVPcoated AgNPs. Furthermore, 40-PVP-AgNP is split between positive and negative scores (close to zero) for principal component 2, indicating that the difference is mainly between the group formed by 40-cit-AgNP and 110-cit-AgNP and the group formed by 110-PVP-AgNP and the control. Therefore, surface coating may be the major factor that determines the toxicity of AgNPs to D. magna compared to particle size.

Validation of RNA-Seq. To validate the reliability of the data obtained from RNA-Seq, a total of eight DEGs, including four up-regulated DEGs and four down-regulated DEGs from the 40-cit-AgNP, 110-cit-AgNP, 40-PVP-AgNP and 110-PVPAgNP treatments, were selected and validated by RT-qPCR. Detailed information about the primers including gene ID, gene symbol, gene description, product size and primer sequences is provided in Table S2. As shown in Figure S3, the RT-qPCR results for the eight DEGs show a high degree of correlation with the trend revealed by RNA-Seq A positive correlation exists $\left(R^{2}=0.933\right)$ between the expression level of DEGs from RNA-Seq and RT-qPCR, confirming the high reproducibility and reliability of the RNA-Seq data.

\section{DISCUSSION}

Coating-specific and size-dependent toxicities of AgNPs were demonstrated in the present study. The $\mathrm{LC}_{50}$ data showed that citrate-coated AgNPs were more toxic than PVP-coated AgNPs and that $40 \mathrm{~nm}$ AgNPs were more toxic than $110 \mathrm{~nm}$ AgNPs. Similar results were obtained from previous studies. Poynton et al. found that the $\mathrm{LC}_{50}$ values of AgNPs in 10-day-old D. magna were $1.8 \mu \mathrm{g} / \mathrm{L}$ for citrate-coated AgNPs and $10.6 \mu \mathrm{g} / \mathrm{L}$ for PVP-coated AgNPs. ${ }^{51}$ The acute toxicity of AgNPs in D. magna demonstrated that citrate-coated AgNPs were less toxic than uncoated AgNPs, and the larger citrate-coated AgNPs (60 and $100 \mathrm{~nm}$ ) exhibited approximately 7.5-fold lower toxicity relative to the smaller citrate-coated AgNPs $(20 \mathrm{~nm}) .{ }^{52}$ Our results were also in agreement with a study on Caenorhabditis elegans, in which it was demonstrated that the PVP coating reduced the toxicity of the AgNPs significantly and that $8 \mathrm{~nm}$ PVP-coated AgNPs were more toxic than 38 nm PVP-coated AgNPs. ${ }^{53}$

Moreover, the toxicity of the AgNPs is directly related to the aggregation of their particles. Aggregation can reduce toxicity. ${ }^{54,55}$ The aggregated AgNPs formed larger clusters that reduced the uptake by cells, whereas the dispersed AgNPs more easily crossed cell membranes and inhibited cell growth. ${ }^{23}$ However, in our study, 40-cit-AgNPs were more toxic than 40PVP- AgNPs even though 40-cit-AgNPs tended to aggregate more. Because the toxicity of AgNPs is not determined by a single factor, a number of factors act in combination to mediate the toxicity of AgNPs. This is in accordance with the previous investigation, which has confirmed that $\mathrm{SO}_{2}$-coated silver nanowires (AgNWs) were more toxic to D. magna than PVPcoated AgNWs, but the $\mathrm{SO}_{2}$-coated AgNWs aggregated and settled more.

Most of the previous studies showed that AgNP toxicities were caused by the release of silver ions, whether they are different coatings or particle sizes. The dissolution rates were time-dependent and varied considerably between the different types of AgNPs. Citrate-coated AgNPs were more reactive than PVP-coated AgNPs. It might be that the stability of the PVP coating enabled the silver to be fully encapsulated. ${ }^{56}$ The stability of the PVP-coated AgNPs was also confirmed by the $\zeta$ potentials. The absolute values of the $\zeta$ potentials for the citrate-coated AgNPs decreased significantly after $24 \mathrm{~h}$ of exposure, suggesting a significant decrease in the AgNP stability and explaining the observed aggregation; in contrast, no obvious changes were observed for the PVP-coated AgNPs, indicating good stability. This result is consistent with previous studies in which citrate-coated AgNPs had a higher dissolution rate than PVP-coated AgNPs. ${ }^{57}$ The PVP-coated AgNPs were more stable than the citrate-coated AgNPs as a result of steric repulsion by the absorbed polymer layer. ${ }^{25}$ These findings indicated that the surface coating was not an impervious barrier and that silvers ion can be released from AgNPs and induce toxicity. Meanwhile, there was a significant difference in the toxicity between 40 and $110 \mathrm{~nm}$ AgNPs. The $40 \mathrm{~nm}$ AgNPs had higher dissolution rates than $110 \mathrm{~nm}$ AgNPs for the same types of surface coating. This may be caused by differences in the release of silver ions. For example, $20 \mathrm{~nm}$ citrate-coated AgNPs released silver ions faster than $110 \mathrm{~nm}$ citrate-coated $\mathrm{AgNPs}^{58}$ and in which $7 \mathrm{~nm}$ AgNPs showed higher dissolution rates than did $40 \mathrm{~nm}$ AgNPs due to the higher specific surface areas and higher enthalpies of formation of the smaller particles. ${ }^{59}$ Silver ions can be also released from AgNPs in the gut or in body fluids, which is the main mechanism of the toxic effects of AgNPs and AgNPs sterilization. AgNP can be ionized in body fluids or the gut, and their interaction with $\mathrm{H}_{2} \mathrm{O}_{2}$ is considered to be one of the factors of the release of $\mathrm{Ag}^{+}$ in the gut. From this mechanism, the surface of AgNPs can quickly release free $\mathrm{Ag}+$ after oxidation. Therefore, the toxic effects could be also explained by the body burden values. The uptake of $40 \mathrm{~nm}$ AgNPs by D. magna is greater than that of 110 $\mathrm{nm}$ AgNPs at the same time point. The body burden of the four types of AgNPs showed a general increase during the first $24 \mathrm{~h}$. The similar results were also concluded from the uptake behaviors of carbon nanotubes by Eisenia fetida. ${ }^{60}$ The uptake of graphene by $D$. magna across the range of concentrations $(25,50,100$, and $250 \mu \mathrm{g} / \mathrm{L})$ increased during the first $24 \mathrm{~h}^{61}$

The toxicity effects of different AgNPs to D. magna were further confirmed by comparative transcriptome analysis. The number of DEGs in D. magna that were altered by citratecoated AgNPs was significantly greater than that by PVP-coated AgNPs, and the number of DEGs in D. magna that were altered by $40 \mathrm{~nm}$ AgNPs was significantly greater than the number altered by $110 \mathrm{~nm}$ AgNPs, supporting the coating-specific and size-dependent toxicity of AgNPs to D. magna. GO enrichment analysis of the DEGs indicated that the number of GO terms in the citrate-coated AgNPs was greater than the number in the PVP-coated AgNPs, which was consistent with the results of the silver ion release. However, $40 \mathrm{~nm}$ was not greater than 110 $\mathrm{nm}$ for the PVP-coated AgNPs, which may be caused by the large number of unannotated genes in the D. magna genome database. Note that most of the DEGs in D. magna that were 
induced by AgNPs were enriched in ion binding-related terms, including "transition metal ion binding", "ion binding", "iron ion binding", and "cation binding", which is consistent with the release trend of silver ion. Ion binding is crucial for numerous biological processes, particularly protein activities involved in these processes. The binding processes between metal ions and active sites of key enzymes in vertebrates are regarded as the basis for enzyme activation. Approximately $1 / 3$ of proteins in vertebrates bind at least one metal ion, including potassium, calcium, sodium, magnesium, copper, iron, zinc, and manganese ions. ${ }^{62,63}$ These metal ions induce conformational changes in the proteins upon binding, which stabilize the protein structure and participate in enzyme catalysis. ${ }^{64}$ In this study, the GO results were consistent with earlier studies on aquatic animals. For example, the metal ion binding related genes of zebrafish embryos were significantly influenced by AgNPs. ${ }^{65} \mathrm{D}$. magna that were exposed to $\mathrm{CuO} \mathrm{NPs}$ for $96 \mathrm{~h}(<50 \mathrm{~nm} ; 1.97 \mathrm{mg} / \mathrm{L})$ also had significant alterations to the genes that encode for metal ion binding proteins. ${ }^{66}$ It can be proposed that silver ions released from AgNPs may compete with other metal ions in binding to functional proteins, resulting in changes to protein structure and function in D. magna.

KEGG analysis also revealed the coating-specific genotoxicity of AgNPs to D. magna. "RNA polymerase" is the only pathway in common among citrate-coated AgNPs, and "protein digestion and absorption" is the only pathway in common among PVP-coated AgNPs. RNA polymerase is an enzyme that catalyzes the transcription of DNA into RNA in the nucleus. RNA polymerase controls the process of transcription, during which the information stored in a molecule of DNA is copied into a new molecule of mRNA. This enzyme controls the synthesis of almost all functional proteins in organisms, which is vital to normal living for these species. Previous studies have documented the toxicity of AgNPs on RNA polymerase in mammalia cells. For example, AgNPs induced significant suppression of RNA polymerase activity and overall RNA transcription in erythroid progenitor cells through direct binding of $\mathrm{Ag}$ to RNA polymerase. ${ }^{67}$ Changes in the expressions of genes involved in the RNA polymerase pathway may influence the transcription process of some important functional genes, which will cause the reduction or deletion of protein function and result in adverse effects on D. magna. This may be the major molecular mechanism for the greater toxicity of citrate-coated AgNPs. As the only in-common response to PVP-coated AgNP exposure, "protein digestion and absorption" is an important regulatory pathway for nutrient absorption, which is essential for the digestion and absorption of proteins in food. These proteins are used by the bodies of animals to repair and build cells or to create enzymes, neurotransmitters, DNA, and RNA. To date, there has been no report on the effects of nanoparticles on digestion and absorption of proteins. The enrichment of genes involved in protein digestion and absorption implies significant influence of PVP-coated AgNPs on the feeding and digestive systems, which will affect the energy source and reduce the resistance of $D$. magna, leading to an increase in disease and mortality.

Here, 40-cit-AgNP was the most toxic treatment among the four types of AgNPs. As the most statistically significant pathway for 40-cit-AgNP, the "hippo signaling pathway" ( $q=$ 0.0211 ), first discovered in Drosophila, ${ }^{68}$ is an important regulatory pathway that controls the size and morphology of animal organs. Changes in this pathway can cause the head of Drosophila to look like that of a hippopotamus due to tissue overgrowth. ${ }^{69}$ In this study, the genes in this pathway were significantly enriched in the $D$. magna that were incubated in 40-cit-AgNP, suggesting the underlying impact of these nanoparticles on the morphology of this species (in that they may cause deformity or death). The result supports the conclusion that 40 -cit-AgNP is the most toxic nanoparticle. In addition, 40-PVP-AgNP induced significant changes in the "lysosome" pathway $\left(q=8.62 \times 10^{-5}\right)$. A lysosome is a vacuole that is surrounded by a lipid membrane and filled with a series of acid hydrolases. Senescent organelles and macromolecules are trapped and digested in lysosomes during cell differentiation processes. ${ }^{70}$ Oxidative stress induced by the overproduction of ROS is the most widely studied and accepted mechanism of nanotoxicity. ${ }^{71,72}$ The oxidative damage caused by nanoparticles can produce a large amount of cell debris or protein fragments that need to be removed. ${ }^{73}$ These waste products are harmful to the cell if they are not cleaned up in time. The change in the lysosome pathway is apparently a sign of body damage, suggesting the greater impact of 40-PVP-AgNP on D. magna. This further confirms that the effects of AgNPs on D. magna are size-dependent.

Summarily, the citrate-coated AgNPs and $40 \mathrm{~nm}$ AgNPs exerted a lower $\mathrm{LC}_{50}$ value, caused a higher silver dissolution rate, and induced a higher number of DEGs in D. magna, suggesting that the citrate-coated AgNPs were more toxic than PVP-coated AgNPs, and smaller AgNPs (40 nm) were more toxic than the larger AgNPs $(110 \mathrm{~nm})$. The comparative transcriptome analysis demonstrated that the toxic effects of AgNPs on D. magna were correlated with the molecular mechanisms of ion binding and several metabolic pathways especially for the "RNA polymerase" and "protein digestion and absorption" pathways. These results suggested that AgNPs could induce toxicity in a size- and coating-dependent manner, which could help us to better understand the possible mechanism of AgNP toxicity in aquatic invertebrates at the transcriptome level and therefore provide important insights into the broad impacts of nanoparticles on aquatic environments.

\section{ASSOCIATED CONTENT}

\section{S Supporting Information}

The Supporting Information is available free of charge on the ACS Publications website at DOI: 10.1021/acs.est.7b03918.

Tables showing the chemical composition of Bold's basal medium and primer sequences used in RT-qPCR. Figures showing $\mathrm{LC}_{50}$ values, a heatmap for the hierarchical cluster analysis, and the validation of RNASeq by RT-qPCR. (PDF)

A table showing differentially expressed genes for 40-citAgNP, 110-cit-AgNP, 40-PVP-AgNP, and 110-PVPAgNP. (XLSX)

A table showing enrichment GO terms for 40-cit-AgNP, 110-cit-AgNP, 40-PVP-AgNP, and 110-PVP-AgNP. (XLSX)

A table showing enriched KEGG pathways for 40-citAgNP, 110-cit-AgNP, 40-PVP-AgNP, and 110-PVPAgNP. (XLSX)

\section{AUTHOR INFORMATION}

\section{Corresponding Author}

*E-mail: xkwang@ncepu.edu.cn. 


\section{ORCID}

Jing Hou: 0000-0003-0244-1398

Shiguo Li: 0000-0002-1578-8844

Xiangke Wang: 0000-0002-3352-1617

\section{Notes}

The authors declare no competing financial interest.

\section{ACKNOWLEDGMENTS}

Financial support from NSFC (grant nos. 21225730, 91326202, 21577032, and 21607043), the Fundamental Research Funds for the Central Universities (grant nos. 2016ZZD06 and JB2015001), the Open Project of Key Laboratory of Environmental Biotechnology, CAS (grant no. kf2016009), the Jiangsu Provincial Key Laboratory of Radiation Medicine and Protection, and the Priority Academic Program Development of Jiangsu Higher Education Institutions are acknowledged.

\section{REFERENCES}

(1) Van der Zande, M.; Vandebriel, R. J.; Van Doren, E.; Kramer, E.; Herrera Rivera, Z.; Serrano-Rojero, C. S.; Gremmer, E. R.; Mast, J.; Peters, R. J. B.; Hollman, P. C. H.; Hendriksen, P. J. M.; Marvin, H. J. P.; Peijnenburg, A. A. C. M.; Bouwmeester, H. Distribution, elimination, and toxicity of silver nanoparticles and silver ions in rats after 28-day oral exposure. ACS Nano 2012, 6 (8), 7427-7442.

(2) Moulton, M. C.; Braydich-Stolle, L. K.; Nadagouda, M. N.; Kunzelman, S.; Hussain, S. M.; Varma, R. S. Synthesis, characterization and biocompatibility of "green" synthesized silver nanoparticles using tea polyphenols. Nanoscale 2010, 2 (5), 763-770.

(3) Ji, J. H.; Jung, J. H.; Kim, S. S.; Yoon, J.; Park, J. D.; Choi, B. S.; Chung, Y. H.; Kwon, I. H.; Jeong, J.; Han, B. S.; Shin, J. H.; Sung, J. H.; Song, K. S.; Yu, I. J. Twenty-eight-day inhalation toxicity study of silver nanoparticles in Sprague-Dawley rats. Inhalation Toxicol. 2007, 19 (10), 857-871.

(4) Osborne, O. J.; Lin, S.; Chang, C. H.; Ji, Z.; Yu, X.; Wang, X.; Lin, S.; Xia, T.; Nel, A. E. Organ-specific and size-dependent Ag nanoparticle toxicity in gills and intestines of adult zebrafish. ACS Nano 2015, 9 (10), 9573-9584.

(5) Dhar, S.; Murawala, P.; Shiras, A.; Pokharkar, V.; Prasad, B. L. V. Gellan gum capped silver nanoparticle dispersions and hydrogels: cytotoxicity and in vitro diffusion studies. Nanoscale 2012, 4 (2), 563567.

(6) D’Britto, V.; Kapse, H.; Babrekar, H.; Prabhune, A. A.; Bhoraskar, S. V.; Premnath, V.; Prasad, B. L. V. Silver nanoparticle studded porous polyethylene scaffolds: bacteria struggle to grow on them while mammalian cells thrive. Nanoscale 2011, 3 (7), 2957-2963.

(7) Han, M. H.; Lin, H. F.; Yuan, Y. H.; Wang, D. Z.; Jin, Y. Pressure drop for two phase counter-current flow in a packed column with a novel internal. Chem. Eng. J. 2003, 94 (3), 179-187.

(8) Wang, H. H.; Liu, C. Y.; Wu, S. B.; Liu, N. W.; Peng, C. Y.; Chan, T. H.; Hsu, C. F.; Wang, J. K.; Wang, Y. L. Highly raman-enhancing substrates based on silver nanoparticle arrays with tunable sub-10 nm gaps. Adv. Mater. 2006, 18 (4), 491.

(9) Ip, M.; Lui, S. L.; Poon, V. K. M.; Lung, I.; Burd, A. Antimicrobial activities of silver dressings: an in vitro comparison. J. Med. Microbiol. 2006, 55 (1), 59-63.

(10) Navarro, E.; Piccapietra, F.; Wagner, B.; Marconi, F.; Kaegi, R.; Odzak, N.; Sigg, L.; Behra, R. Toxicity of silver nanoparticles to Chlamydomonas reinhardtii. Environ. Sci. Technol. 2008, 42 (23), 8959-8964.

(11) George, S.; Lin, S.; Ji, Z.; Thomas, C. R.; Li, L.; Mecklenburg, M.; Meng, H.; Wang, X.; Zhang, H.; Xia, T.; Hohman, J. N.; Lin, S.; Zink, J. I.; Weiss, P. S.; Nel, A. E. Surface defects on plate-shaped silver nanoparticles contribute to its hazard potential in a fish gill cell line and zebrafish embryos. ACS Nano 2012, 6 (5), 3745-3759.

(12) McTeer, J.; Dean, A. P.; White, K. N.; Pittman, J. K. Bioaccumulation of silver nanoparticles into Daphnia magna from a freshwater algal diet and the impact of phosphate availability. Nanotoxicology 2014, 8 (3), 305-316.

(13) Sotiriou, G. A.; Pratsinis, S. E. Antibacterial Activity of Nanosilver Ions and Particles. Environ. Sci. Technol. 2010, 44 (14), 5649-5654.

(14) Pal, S.; Tak, Y. K.; Song, J. M. Does the antibacterial activity of silver nanoparticles depend on the shape of the nanoparticle? A study of the gram-negative bacterium Escherichia coli. Appl. Environ. Microb. 2007, 73 (6), 1712-1720.

(15) Yang, X.; Gondikas, A. P.; Marinakos, S. M.; Auffan, M.; Liu, J.; Hsu-Kim, H.; Meyer, J. N. Mechanism of silver nanoparticle toxicity is dependent on dissolved silver and surface coating in Caenorhabditis elegans. Environ. Sci. Technol. 2012, 46 (2), 1119-1127.

(16) El Badawy, A. M.; Silva, R. G.; Morris, B.; Scheckel, K. G.; Suidan, M. T.; Tolaymat, T. M. Surface charge-dependent toxicity of silver nanoparticles. Environ. Sci. Technol. 2011, 45 (1), 283-287.

(17) Choi, O.; Clevenger, T. E.; Deng, B.; Surampalli, R. Y.; Ross, L., Jr.; $\mathrm{Hu}, \mathrm{Z}$. Role of sulfide and ligand strength in controlling nanosilver toxicity. Water Res. 2009, 43 (7), 1879-1886.

(18) Kawata, K.; Osawa, M.; Okabe, S. In vitro toxicity of silver nanoparticles at noncytotoxic doses to HepG2 human hepatoma cells. Environ. Sci. Technol. 2009, 43 (15), 6046-6051.

(19) Osborne, O. J.; Johnston, B. D.; Moger, J.; Balousha, M.; Lead, J. R.; Kudoh, T.; Tyler, C. R. Effects of particle size and coating on nanoscale $\mathrm{Ag}$ and $\mathrm{TiO}_{2}$ exposure in zebrafish (Danio rerio) embryos. Nanotoxicology 2013, 7 (8), 1315-1324.

(20) Andrei, J.; Pain-Devin, S.; Felten, V.; Devin, S.; Giamberini, L.; Mehennaoui, K.; Cambier, S.; Gutleb, A. C.; Guerold, F. Silver nanoparticles impact the functional role of Gammarus roeseli (Crustacea Amphipoda). Environ. Pollut. 2016, 208 (B), 608-618.

(21) Kim, T. H.; Kim, M.; Park, H. S.; Shin, U. S.; Gong, M. S.; Kim, H. W. Size-dependent cellular toxicity of silver nanoparticles. J. Biomed. Mater. Res., Part A 2012, 100 A (4), 1033-1043.

(22) Cong, Y.; Banta, G. T.; Selck, H.; Berhanu, D.; Valsami-Jones, E.; Forbes, V. E. Toxicity and bioaccumulation of sediment-associated silver nanoparticles in the estuarine polychaete. Aquat. Toxicol. 2014, 156, 106-115.

(23) Rosario, F.; Hoet, P.; Santos, C.; Oliveira, H. Death and cell cycle progression are differently conditioned by the AgNP size in osteoblast-like cells. Toxicology 2016, 368, 103-115.

(24) Jimenez-Lamana, J.; Slaveykova, V. I. Silver nanoparticle behaviour in lake water depends on their surface coating. Sci. Total Environ. 2016, 573, 946-953.

(25) Huynh, K. A.; Chen, K. L. Aggregation kinetics of citrate and polyvinylpyrrolidone coated silver nanoparticles in monovalent and divalent electrolyte solutions. Environ. Sci. Technol. 2011, 45 (13), 5564.

(26) Colman, B. P.; Espinasse, B.; Richardson, C. J.; Matson, C. W.; Lowry, G. V.; Hunt, D. E.; Wiesner, M. R.; Bernhardt, E. S. Emerging Contaminant or an Old Toxin in Disguise? Silver Nanoparticle Impacts on Ecosystems. Environ. Sci. Technol. 2014, 48 (9), 52295236.

(27) Yuan, Z.; Li, J.; Cui, L.; Xu, B.; Zhang, H.; Yu, C. Interaction of silver nanoparticles with pure nitrifying bacteria. Chemosphere 2013, 90 (4), 1404-1411.

(28) Hou, J.; Liu, X. H.; Wang, J.; Zhao, S. N.; Cui, B. S. Microarraybased analysis of gene expression in Lycopersicon esculentum seedling roots in response to cadmium, chromium, mercury, and lead. Environ. Sci. Technol. 2015, 49 (3), 1834-1841.

(29) Hou, J.; Liu, X. H.; Cui, B. S.; Bai, J. H.; Wang, X. K. Microarray analysis and real-time PCR assay developed to find biomarkers for mercury-contaminated soil. Toxicol. Res. 2016, 5 (6), 1539-1547.

(30) Li, S.; Huang, J.; Liu, C.; Liu, Y.; Zheng, G.; Xie, L.; Zhang, R. Interactive effects of seawater acidification and elevated temperature on the transcriptome and biomineralization in the Pearl oyster pinctada fucata. Environ. Sci. Technol. 2016, 50 (3), 1157-1165.

(31) Li, S.; Liu, C.; Huang, J.; Liu, Y.; Zhang, S.; Zheng, G.; Xie, L.; Zhang, R. Transcriptome and biomineralization responses of the pearl 
oyster Pinctada fucata to elevated $\mathrm{CO}_{2}$ and temperature. Sci. Rep. 2016, 6 (18943).10.1038/srep18943

(32) Kim, W. J.; Shin, E. H.; Kong, H. J.; Kim, H. S.; Kim, B. S.; Nam, B. H.; Kim, Y. O.; Kim, C. H.; Jung, H.; An, C. M. Characterization of novel microsatellite markers derived from Korean rose bitterling (Rhodeus uyekii) genomic library. GMR, Genet. Mol. Res. 2014, 13 (4), 8147-8152.

(33) Griffitt, R. J.; Hyndman, K.; Denslow, N. D.; Barber, D. S. Comparison of molecular and histological changes in zebrafish gills exposed to metallic nanoparticles. Toxicol. Sci. 2009, 107 (2), 404415.

(34) Hou, J.; Liu, X. H.; Cui, B. S.; Bai, J. H.; Wang, X. K. Concentration- dependent alterations in gene expression induced by cadmium in Solanum lycopersicum. Environ. Sci. Pollut. Res. 2017, 24 (11), 10528-10536.

(35) Kawahara-Miki, R.; Wada, K.; Azuma, N.; Chiba, S. Expression profiling without genome sequence information in a non-model species, pandalid shrimp (Pandalus latirostris), by Next-Generation Sequencing. PLoS One 2011, 6 (10).e2604310.1371/journal.pone. 0026043

(36) Micallef, G.; Bickerdike, R.; Reiff, C.; Fernandes, J. M.; Bowman, A. S.; Martin, S. A. Exploring the transcriptome of Atlantic salmon (Salmo salar) skin, a major defense organ. Mar. Biotechnol. 2012, 14 (5), 559-569.

(37) Huang, Q.; Dong, S.; Fang, C.; Wu, X.; Ye, T.; Lin, Y. Deep sequencing-based transcriptome profiling analysis of Oryzias melastigma exposed to PFOS. Aquat. Toxicol. 2012, 120, 54-58.

(38) Robinson, N.; Sahoo, P. K.; Baranski, M.; Mahapatra, K. D.; Saha, J. N.; Das, S.; Mishra, Y.; Das, P.; Barman, H. K.; Eknath, A. E. Expressed sequences and polymorphisms in rohu carp (Labeo rohita, Hamilton) revealed by mRNA-Seq. Mar. Biotechnol. 2012, 14 (5), 620-633.

(39) Xiang, L.; He, D.; Dong, W.; Zhang, Y.; Shao, J. Deep sequencing-based transcriptome profiling analysis of bacteria-challenged Lateolabrax japonicus reveals insight into the immune-relevant genes in marine fish. BMC Genomics 2010, 11 (472).47210.1186/ 1471-2164-11-472

(40) Zeng, D.; Chen, X.; Xie, D.; Zhao, Y.; Yang, C.; Li, Y.; Ma, N.; Peng, M.; Yang, Q.; Liao, Z. Transcriptome analysis of Pacific white shrimp (Litopenaeus vannamei) hepatopancreas in response to Taura syndrome Virus (TSV) experimental infection. PLoS One 2013, 8 (2), e57515.

(41) Martín-Gómez, L.; Villalba, A.; Carballal, M. J.; Abollo, E. Identification of relevant cancer related-genes in the flat oyster Ostrea edulis affected by disseminated neoplasia. Mar. Biotechnol. 2013, 15 (2), 159-174.

(42) Wang, J.; Gao, J.; Xie, J.; Zheng, X.; Yan, Y.; Li, S.; Xie, L.; Zhang, R. Cloning and mineralization-related functions of the calponin gene in Chlamys farreri. Comp. Biochem. Physiol., Part B: Biochem. Mol. Biol. 2016, 201, 53-58.

(43) Werner, G. D.; Gemmell, P.; Grosser, S.; Hamer, R.; Shimeld, S. M. Analysis of a deep transcriptome from the mantle tissue of Patella vulgata Linnaeus (Mollusca: Gastropoda: Patellidae) reveals candidate biomineralising genes. Mar. Biotechnol. 2013, 15 (2), 230-243.

(44) Lyu, K.; Meng, Q.; Zhu, X.; Dai, D.; Zhang, L.; Huang, Y.; Yang, Z. Changes in iTRAQ-based proteomic profiling of the cladoceran Daphnia magna exposed to microcystin-producing and microcystinfree Microcystis aeruginosa. Environ. Sci. Technol. 2016, 50 (9), 47984807.

(45) Watanabe, H.; Kobayashi, K.; Kato, Y.; Oda, S.; Abe, R.; Tatarazako, N.; Iguchi, T. Transcriptome profiling in crustaceans as a tool for ecotoxicogenomics. Cell Biol. Toxicol. 2008, 24 (6), 641-647.

(46) Zhang, X.; Xia, X.; Li, H.; Zhu, B.; Dong, J. Bioavailability of pyrene associated with suspended sediment of different grain sizes to Daphnia magna as investigated by passive dosing devices. Environ. Sci. Technol. 2015, 49 (16), 10127-10135.

(47) Schwarzenberger, A.; Sadler, T.; Motameny, S.; Ben-Khalifa, K.; Frommolt, P.; Altmüller, J.; Konrad, K.; von Elert, E. Deciphering the genetic basis of microcystin tolerance. BMC Genomics 2014, 15 (1), 776.

(48) Shen, M.; Zhou, X.; Yang, X.; Chao, J.; Liu, R.; Liu, J. Exposure Medium: Key in identifying free $\mathrm{Ag}+$ as the exclusive species of silver nanoparticles with acute toxicity to Daphnia magna. Sci. Rep. 2015, 5 (1).10.1038/srep09674

(49) U.S. Environmental Protection Agency. Methods for Measuring the Acute Toxicity of Effluents and Receiving Waters to Freshwater and Marine Organisms; report no. EPA/812/R/02/012; Office of Water: Washington, D.C., 2002.

(50) Garcia-Reyero, N.; Poynton, H. C.; Kennedy, A. J.; Guan, X.; Escalon, B. L.; Chang, B.; Varshavsky, J.; Loguinov, A. V.; Vulpe, C. D.; Perkins, E. J. Biomarker discovery and transcriptomic responses in Daphnia magna exposed to munitions constituents. Environ. Sci. Technol. 2009, 43 (11), 4188-4193.

(51) Poynton, H. C.; Lazorchak, J. M.; Impellitteri, C. A.; Blalock, B. J.; Rogers, K.; Allen, H. J.; Loguinov, A.; Heckman, J. L.; Govindasmawy, S. Toxicogenomic responses of nanotoxicity in Daphnia magna exposed to silver nitrate and coated silver nanoparticles. Environ. Sci. Technol. 2012, 46 (11), 6288-6296.

(52) Seitz, F.; Rosenfeldt, R. R.; Storm, K.; Metreveli, G.; Schaumann, G. E.; Schulz, R.; Bundschuh, M. Effects of silver nanoparticle properties, media $\mathrm{pH}$ and dissolved organic matter on toxicity to Daphnia magna. Ecotox. Ecotoxicol. Environ. Saf. 2015, 111 263-270.

(53) Ahn, J.; Eom, H.; Yang, X.; Meyer, J. N.; Choi, J. Comparative toxicity of silver nanoparticles on oxidative stress and DNA damage in the nematode. Chemosphere 2014, 108, 343-352.

(54) Levard, C.; Hotze, E. M.; Lowry, G. V.; Brown, G. E., Jr Environmental transformations of silver nanoparticles: impact on stability and toxicity. Environ. Sci. Technol. 2012, 46 (13), 6900-6914.

(55) Zhou, D.; Keller, A. A. Role of morphology in the aggregation kinetics of $\mathrm{ZnO}$ nanoparticles. Water Res. 2010, 44 (9), 2948-2956.

(56) Scanlan, L. D.; Reed, R. B.; Loguinov, A. V.; Antczak, P.; Tagmount, A.; Aloni, S.; Nowinski, D. T.; Luong, P.; Tran, C.; Karunaratne, N.; Pham, D.; Lin, X. X.; Falciani, F.; Higgins, C. P.; Ranville, J. F.; Vulpe, C. D.; Gilbert, B. Silver nanowire exposure results in internalization and toxicity to Daphnia magna. ACS Nano 2013, 7 (12), 10681-10694.

(57) Angel, B. M.; Batley, G. E.; Jarolimek, C. V.; Rogers, N. J. The impact of size on the fate and toxicity of nanoparticulate silver in aquatic systems. Chemosphere 2013, 93 (2), 359-365.

(58) Wang, X.; Ji, Z.; Chang, C. H.; Zhang, H.; Wang, M.; Liao, Y. P.; Lin, S.; Meng, H.; Li, R.; Sun, B.; et al. Use of coated silver nanoparticles to understand the relationship of particle dissolution and bioavailability to cell and lung toxicological potential. Small 2014, 10 (2), 385-398.

(59) MacCuspie, R. I. Colloidal stability of silver nanoparticles in biologically relevant conditions. J. Nanopart. Res. 2011, 13 (7), 28932908.

(60) Petersen, E. J.; Huang, Q. G.; Weber, W. J., Jr. Bioaccumulation of radio-labeled carbon nanotubes by Eisenia foetida. Environ. Sci. Technol. 2008, 42 (8), 3090-3095.

(61) Guo, X. K.; Dong, S. P.; Petersen, E. J.; Gao, S. X.; Huang, Q. G.; Mao, L. Biological uptake and depuration of radio-labeled graphene by Daphnia magna. Environ. Sci. Technol. 2013, 47 (21), 12524-12531.

(62) Lu, C.; Lin, Y.; Lin, J.; Yu, C. Prediction of Metal Ion-Binding Sites in Proteins Using the Fragment Transformation Method. PLoS One 2012, 7 (6).e3925210.1371/journal.pone.0039252

(63) Shi, W.; Chance, M. R. Metallomics and metalloproteomics. Cell. Mol. Life Sci. 2008, 65 (19), 3040-3048.

(64) Frey, P. A. The Leloir pathway: a mechanistic imperative for three enzymes to change the stereochemical configuration of a single carbon in galactose. FASEB J. 1996, 10 (4), 461-470.

(65) Park, H.; Yeo, M. Comparison of gene expression patterns from zebrafish embryos between pure silver nanomaterial and mixed silver nanomaterial containing cells of Hydra magnipapillata. Mol. Cell. Toxicol. 2015, 11 (3), 307-314. 
(66) Adam, N.; Vergauwen, L.; Blust, R.; Knapen, D. Gene transcription patterns and energy reserves in Daphnia magna show no nanoparticle specific toxicity when exposed to $\mathrm{ZnO}$ and $\mathrm{CuO}$ nanoparticles. Environ. Res. 2015, 138, 82-92.

(67) Wang, Z.; Liu, S.; Ma, J.; Qu, G.; Wang, X.; Yu, S.; He, J.; Liu, J.; Xia, T.; Jiang, G. Silver nanoparticles induced RNA polymerase-silver binding and RNA transcription inhibition in erythroid progenitor cells. ACS Nano 2013, 7 (5), 4171-4186.

(68) Ramos, A.; Camargo, F. D. The Hippo signaling pathway and stem cell biology. Trends Cell Biol. 2012, 22 (7), 339-346.

(69) Staley, B. K.; Irvine, K. D. Hippo signaling in Drosophila: recent advances and insights. Dev. Dyn. 2012, 241 (1SI), 3-15.

(70) Settembre, C.; Fraldi, A.; Medina, D. L.; Ballabio, A. Signals from the lysosome: a control centre for cellular clearance and energy metabolism. Nat. Rev. Mol. Cell Biol. 2013, 14 (5), 283-296.

(71) Vale, G.; Mehennaoui, K.; Cambier, S.; Libralato, G.; Jomini, S.; Domingos, R. F. Manufactured nanoparticles in the aquatic environment-biochemical responses on freshwater organisms: a critical overview. Aquat. Toxicol. 2016, 170, 162-174.

(72) Hou, J.; Wang, X. X.; Hayat, T.; Wang, X. K. Ecotoxicological effects and mechanism of $\mathrm{CuO}$ nanoparticles to individual organisms. Environ. Pollut. 2016, 5 (6), 1539-1547.

(73) Awasthi, K. K.; Awasthi, A.; Kumar, N.; Roy, P.; Awasthi, K.; John, P. J. Silver nanoparticle induced cytotoxicity, oxidative stress, and DNA damage in CHO cells. J. Nanopart. Res. 2013, 15 (9).10.1007/ s11051-013-1898-5 